\title{
Using logistic regression to investigate self-efficacy and the predictors for National Council Licensure Examination success for baccalaureate nursing students
}

\author{
Linda A. Silvestri ${ }^{1}$, Michele C. Clark $^{2}$, Sheniz A. Moonie ${ }^{3}$ \\ 1. Department of Nursing, Salve Regina University, Newport, Rhode Island, USA. 2. School of Nursing, University of \\ Nevada, Las Vegas, Las Vegas, Nevada, USA. 3. School of Community Health Sciences, Program of Epidemiology and \\ Biostatistics, University of Nevada, Las Vegas, Nevada, USA \\ Correspondence: Linda A. Silvestri. Address: 4 Cedar Meadows Road, Charlestown, Rhode Island 02813, USA. Email: \\ authorlas@aol.com.
}

Received: June 29, 2012

Accepted: September 12, 2012

Online Published: December 26, 2012

DOI : $10.5430 /$ jnep.v3n6p21

URL: http://dx.doi.org/10.5430/jnep.v3n6p21

\section{Abstract}

Objectives: Ensuring success on the National Council Licensure Examination (NCLEX ${ }^{\text {) }}$ ) is a complex role for nurse educators. It is vital that nurse educators attain knowledge about the predictors of NCLEX success so they can design strategies and interventions to optimize student performance. Numerous studies are noted that examined the predictors for NCLEX success, reflecting great interest in this area. However, most investigated the academic predictors; few studies examined the nonacademic predictors. The purpose of this study was to identify the effect of selected academic, nonacademic, and self-efficacy variables on NCLEX outcomes to provide new knowledge to nursing science about these predictors.

Methods: This quantitative study used Albert Bandura's Social Learning Theory as the theoretical framework to guide its focus. Academic variables were pre-nursing scores/grades and nursing course grades, while the nonacademic variables focused on personal and environmental factors/stressors, primary language spoken, and self-efficacy expectations. A national study was conducted using an online survey. After nursing graduates $(n=196)$ received their NCLEX scores, instruments with established reliability and validity were used to collect data about their experiences while attending school. The instruments included the (1) Recent Life Changes Questionnaire (RLCQ); (2) The Brief Measure of Worry Severity (BMWS); and (3) The General Perceived Self-Efficacy scale. Multiple logistic regression was the primary data analysis method used to identify the variables that influence NCLEX passage. Correlation analysis using Pearson product-moment correlation coefficient was also done to identify relationships existing among self-efficacy, and academic and nonacademic variables of NCLEX passage. The Chi-square test for independence was used to investigate primary language spoken and NCLEX outcome.

Results: Logistic regression findings demonstrated that the medical-surgical grade, home and family events and responsibilities, and self-efficacy expectations were significant variables affecting NCLEX outcomes. Correlation analysis revealed that all academic variables showed a positive correlation with self-efficacy expectations, indicating that as a course grade improved, self-efficacy increased. Also, negative correlations between the nonacademic variables and self-efficacy expectations indicated that as worry or responsibilities increased for the individual, self-efficacy decreased. 
The Chi-square test for independence showed a significant relationship between primary language spoken and NCLEX outcome.

Conclusions: Findings imply that medical-surgical nursing courses need to be a priority in curriculum planning. Another finding demonstrates the influence of self-efficacy on NCLEX passage - the more confident a student is and the more support systems available, the better he or she will perform. This finding points to the critical need for nurse educators to study ways to increase a student's self-confidence. The findings of this study also demonstrated that home and family events and responsibilities influence success. This knowledge may assist nurse educators to consider informing students about the need for them to seek out assistance from faculty if home and family events present obstacles to learning. Finally, it was noted that primary language spoken affects outcome. Nurse educators need to plan curricular strategies that will meet individual student needs by having a variety of support resources in place for these students.

\section{Key words}

Predictors of National Council Licensure Examination, National Council Licensure Examination, Logistic regression, Self-Efficacy

\section{I ntroduction}

The predictors for success on the NCLEX have long been an area of interest for faculty and nursing programs. Pass rates represent a measure of faculty and program effectiveness, and certain pass rates need to be attained by a program to maintain accreditation ${ }^{[1]}$. Additionally, competent nurses are needed in the workplace to meet the health care needs of clients served by the profession.

Since the 1980s, multiple studies have explored predictors for NCLEX success. However, results from empirical studies identifying academic predictors have been conflicting. Some studies show that students who were successful on NCLEX had significantly higher science grades, Scholastic Aptitude Test (SAT), and American College Test Assessment (ACT) scores as compared to students who failed ${ }^{[2-5]}$. Still, other studies also demonstrated that entrance criteria, standardized exams, nursing theory grades, and grade point average (GPA) significantly relate to NCLEX success ${ }^{[6-15]}$.

Some examples of the conflicting results begin with Campbell and Dickson's (1996) 10-year evaluation study that noted GPA averages and grades in science courses were the best predictors of NCLEX success ${ }^{[7]}$. These researchers also reported that the least predictive of the variables were exam scores on SATs and nursing courses ${ }^{[7]}$. However, the findings of Daley, Kirkpatrick, Frazier, Chung, and Moser (2003) differed. Their data demonstrated that the final course grade for a senior-level medical-surgical nursing course and cumulative GPA were the only program variables consistent with success ${ }^{[4]}$. Mills, Becker, Sampel, and Pohlman (1992) concurred and found that the best time for predicting NCLEX performance was at the end of the nursing program and that GPA average was the only significant predictor at this point in the program ${ }^{[16]}$. Despite these findings, Waterhouse, Carroll, and Beeman's (1993) study showed the first senior level nursing course grades and graduation GPA were the best predictors ${ }^{[17]}$.

More recent studies looked at other variables. For example, Stuenkel (2006) studied the relationship of several nursing course grades (pharmacology, pathophysiology, medical-surgical, maternal-child, mental health, community, and leadership) to NCLEX success and concluded that those who passed NCLEX held higher mean scores for nursing theory grades ${ }^{[14]}$. Conversely, Beeman and Waterhouse (2001) indicated the variables significantly related to NCLEX success were grades in Nursing Foundations, Pathophysiology II, Wellness Nursing, and Restorative Nursing Interventions I and II $^{[18]}$.

In addition, research studies have shown that nursing course grades consistently have some predictive value for success with NCLEX. The number of "Cs" received in nursing courses was reported to be a stronger predictor of NCLEX failure, thus the more "Cs" earned, the greater the risk ${ }^{[6,18,19]}$. Other researchers note that even one nursing course failure is 
associated with NCLEX failure ${ }^{[2,5,20]}$. Furthermore, some researchers note that the National League for Nursing (NLN) Achievement tests taken during the nursing program were predictive of performance on NCLEX. Nevertheless, most researchers found that end-of-program exit exams were the strongest predictors of NCLEX outcomes ${ }^{[3,19,21,22]}$.

Despite the interest in academic predictors of NCLEX success, a few researchers have been interested in nonacademic predictors, such as test anxiety, self-esteem, and personal and environmental issues. For example, Arathuzik and Aber (1998) noted significant correlations between success and lack of family demands or responsibilities, lack of emotional stress, and sense of competency ${ }^{[23]}$. Additionally, they indicated that students who did not speak English as the primary language at home did not do well on NCLEX ${ }^{[23]}$.

Poorman and Martin (1991) conducted a study that addressed nonacademic predictors and looked at the relationship between performance on the NCLEX and differences in test anxiety, cognitions related to testing, and academic performance. These researchers concluded that variables other than academic ones were the best predictors of actual NCLEX scores and these nonacademic variables included self-predicted NCLEX scores and self-perceived grades ${ }^{\text {[24] }}$. Additionally, they noted that those who passed the NCLEX experienced more facilitative thoughts during major nursing examinations and were more likely to consider themselves good test-takers as compared to those who failed ${ }^{[24]}$.

These results are expected when we know that test anxiety and stress have been linked to performance on exams ${ }^{[25,26]}$. Specifically, Hight's results showed that nursing students had higher anxiety scores than the national norms for college students ${ }^{[25]}$. Furthermore, Campbell and Dickson's (1996) results supported Hight's when they found that test anxiety and self-concept/esteem showed some correlation with NCLEX success ${ }^{[7]}$.

Since the introduction of Bandura's Social Learning Theory, the construct of self-efficacy has been widely studied in psychology in an attempt to understand and predict human behavior ${ }^{[27-29]}$. However, studies that specifically investigated self-efficacy and NCLEX success were not located in the literature. Nevertheless, there are numerous studies that demonstrate self-efficacy's importance for students' success in a general academic and practice setting ${ }^{[28,30-37]}$. For example, Schunk highlights research that evaluates how self-efficacy influences motivation and performance as well as goals and achievement outcomes ${ }^{[35,36]}$. Also, numerous research studies demonstrated that self-efficacy beliefs can predict college students' academic performance and persistence including their success in the academic and practice setting ${ }^{[34,}$ 37-39].

In nursing education, the number of self-efficacy studies is limited and only relate to specific areas of the educational experience. For example, Goldenberg, Iwasiw, and MacMaster (1997) explored self-efficacy expectations of senior baccalaureate nursing students and preceptors ${ }^{[40]}$. Mandorin and Iwasiw (1999) conducted a study only looking at the effects of computer-assisted instruction on the self-efficacy of baccalaureate nursing students in learning theory ${ }^{[41]}$. Andrew (1998) focused his investigation to whether self-efficacy can predict academic performance in the sciences of a first-year undergraduate nursing course ${ }^{[42]}$. Hodge (1999) assessed self-efficacy's effect on achievement in mathematical calculations ${ }^{[43]}$. Nevertheless, all of these research studies demonstrated a strong relationship between self-efficacy and performance $^{[40-43]}$.

Harvey and McMurray (1994) expanded the study of self-efficacy by conducting a study of academic and clinical self-efficacy. Their data demonstrated course withdrawal when undergraduate nursing students had low academic self-efficacy factors (but not clinical self-efficacy) ${ }^{[44]}$.

The inconsistent results on academic predictors noted in the literature and the lack of research on predictors of passing the nursing licensure exam led to the present study. Therefore, the purpose of this study was to evaluate the effect of academic and nonacademic variables on NCLEX passage as the following research questions were posed: 
- Which academic or self-efficacy variables influence NCLEX passage for a student in a baccalaureate degree nursing program?

- Which nonacademic or self-efficacy variables influence NCLEX passage for a student in a baccalaureate degree nursing program?

- What relationships exist among self-efficacy, academic, and nonacademic variables of NCLEX passage for a student in a baccalaureate degree nursing program?

\section{Conceptual framework}

The theoretical framework guiding this study was Albert Bandura's Social Learning Theory. According to this theory, behavior is regulated antecedently through cognitive processes and psychosocial experiences. These processes and experiences affect self-efficacy and determine the response consequences; that is, whether the individual will perceive self-efficacy as high or low.

Thus, self-efficacy expectations are focused on the person's belief in their own capacity to carry out particular behaviors ${ }^{[27]}$. These expectations determine the behaviors a person chooses to perform, their degree of perseverance, and the quality of the performance. Bandura (2012) notes that self-efficacy in part mediates the relation of past academic achievement to subsequent achievement (p.39) ${ }^{[45]}$. Thus, the construct of self-efficacy is a way to understand and predict individual behavior. As applied to this study, a nursing student's generalized self-efficacy expectations are influenced by academic and non-academic variables, which could influence the student to persevere under challenging situations. The NCLEX ${ }^{\circledR}$ Self-Efficacy Expectations Model developed for this study (see Figure 1) highlights that generalized self-efficacy should influence a positive outcome with the NCLEX. Conversely, low generalized self-efficacy expectations could lead to self-doubt about one's ability to achieve success.

ACADEMIC VARIABLES

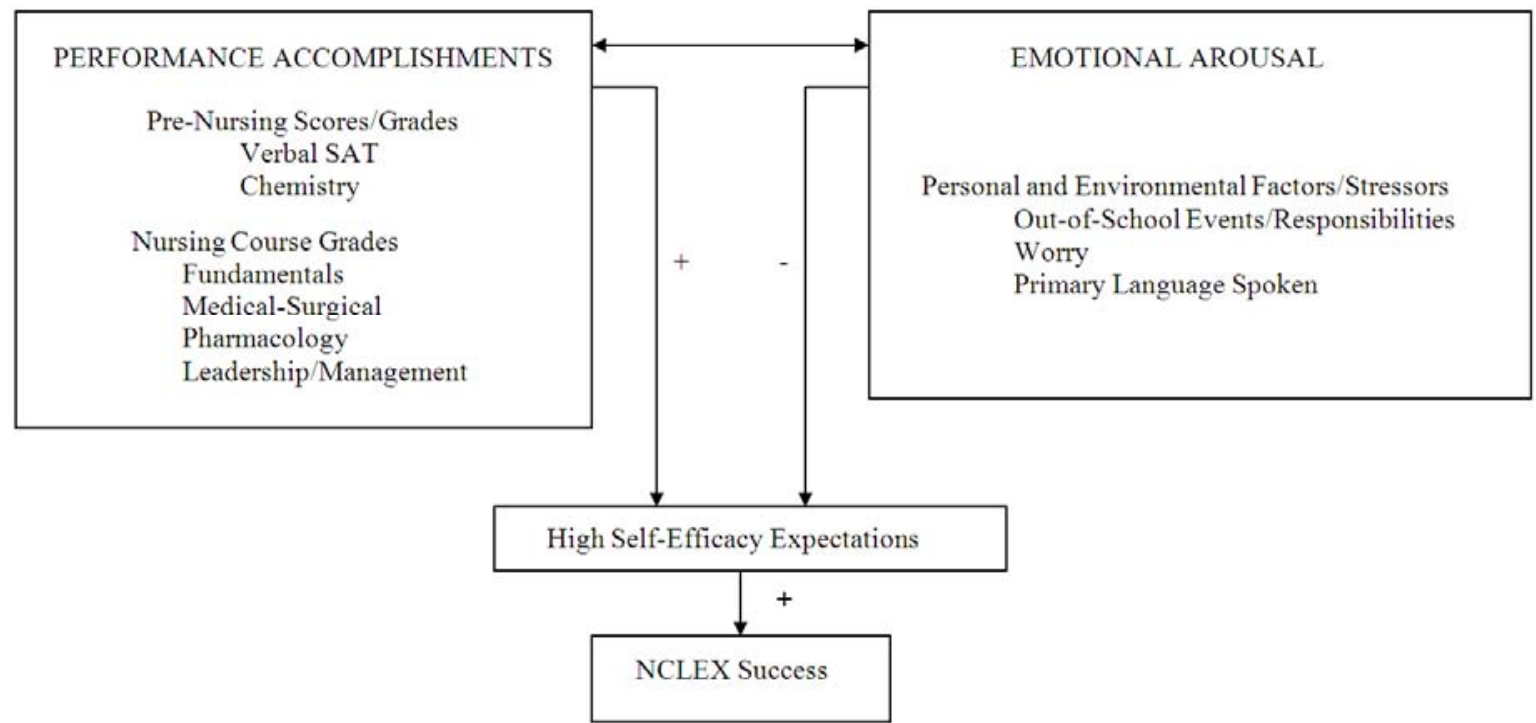

Figure 1. Self-Efficacy Expectations for NCLEX ${ }^{\circledR}$ Success Model

Emotional arousal also serves as a source of self-efficacy expectations. From a psychological perspective, Bandura (1977) described this perspective as the emotional state that results from a threat ${ }^{[27]}$. When Bandura (1977) discussed the processes of learning, he emphasized that if an individual is going to learn, he or she must be paying attention ${ }^{[27]}$. 
Therefore, if attention is reduced or distracted by competing stimuli, then learning is disrupted. Personal or environmental factors/stressors could act as competing stimuli during the educational process and can affect successful achievement.

Specific to this study, emotional arousal is defined as a mood state that can be extreme, indicating that the student is threatened by personal and environmental factors/stressors; or low, indicating that threats from personal and environmental factors/stressors are minimal. Bandura (1977) also proposed that levels of self-efficacy expectations are influenced by the degree of the emotional arousal and the resulting level of worry ${ }^{[27]}$. When threats result in a high state of emotional arousal, increased levels of worry may result, whereas minimal threats should result in low levels of worry ${ }^{[27]}$. Therefore, personal and environmental factors/stressors that cause an increased emotional arousal and level of worry can be threatening to the student and lower self-efficacy expectations. Conversely, a student is more likely to hold high self-efficacy expectations and achieve successful accomplishments if he or she is not experiencing an increased emotional arousal state or worry.

The NCLEX® Self-Efficacy Expectations Model (see Figure 1) shows that selected pre-nursing and nursing course grades (verbal SAT, chemistry, fundamentals, medical-surgical, pharmacology, leadership-management) are related to the concept of performance accomplishments. Personal and environmental factors/stressors (out-of-school responsibilities, worry, and primary language spoken) relate to the concept of emotional arousal. Moreover, primary language spoken other than English creates numerous stressors for the student, such as translating words and needing additional time for assignments and for completing exams ${ }^{[23,46]}$. As depicted, the model proposes that performance accomplishments, emotional arousal, and self-efficacy expectations directly affect the successful outcome in taking the nursing licensing exam.

\section{Methods}

\subsection{Research design}

A descriptive exploratory design was used to identify the relationships of the study variables for a national sample of graduates who completed their program from a nationally accredited baccalaureate degree nursing program located in the United States (U.S.) in 2009. The binary dependent variable for this study was NCLEX outcomes (pass or fail). Pre-nursing course scores/grades, nursing course grades, personal and environmental factors/stressors, and self-efficacy expectations were the independent variables. An electronic survey method was used to collect data from the participants about their experiences while in nursing school after he or she took the NCLEX for the first time. Once data were collected, a descriptive analysis of the variables and their relationship was completed.

\subsection{Instruments}

Survey Monkey ${ }^{\circledR}$ was used to deliver the survey, which contained 109 items and included questions about the following: (a) demographic data, (b) academic data, (c) personal and environmental factors/stressors, (d) self-efficacy expectations, and (e) NCLEX outcome.

Academic data collection procedures asked each participant to self-report pre-nursing scores/grades and nursing course grades. The pre-nursing scores/grades were the following: (a) SAT total score, (b) SAT verbal score (or the SAT Reasoning Test critical reading score), (c) SAT math score, (d) ACT exam score, and (e) college chemistry grade. Self-reported nursing course grades were the following: (a) fundamentals, (b) medical-surgical, (c) pharmacology, and (d) leadership and management. Categories of selection for nursing course grades included: (a) $A=90-100$, (b) $B=80-89$, (c) $\mathrm{C}=70-79$, (d) $\mathrm{D}=60-69$, and (e) not applicable to me. Participants were asked to record the grade of the most recently taken tests or courses. 
Personal and environmental factors/stressors specifically related to out-of-school events and responsibilities and worry while attending nursing school were evaluated by the Miller and Rahe (1997) Recent Life Changes Questionnaire ${ }^{[47]}$ and the brief measure of worry severity (BMS) self-report ${ }^{[48]}$. Items for the RLCQ related to the following: (a) health, (b) work, (c) home and family, (d) personal and social, and (e) financial. The RLCQ identified 74 life events that have values (Life Change Units) attached to them used to measure life-change events. In the RLCQ, the higher the Life Change Unit (LCU) the greater the negative effect on the individual ${ }^{[47]}$. Miller and Rahe (1997) noted that significant Spearman rho correlation coefficients of 0.84 to 0.96 are consistently demonstrated with the RLCQ when comparing demographically divided groups ${ }^{[47]}$. For this study, the instrument was used to identify subscales that may have a negative effect on the individual and predict an outcome.

Worry experienced while attending nursing school was investigated using the 8-question Brief Measure of Worry Severity (BMWS) self-report measure developed by Gladstone, Parker, Mitchell, Malhi, Wilhelm, and Paule-Austin (2005) that demonstrated Cronbach's coefficient alphas ranging from 0.79 to $0.87^{[48]}$. As designed by the authors, a 4-point Likert scale with the ratings of: $1=$ not true at all, $2=$ somewhat true, $3=$ moderately true, and $4=$ definitely true was used. Each item in the tool measured a characteristic of dysfunctional worry so that higher scores indicated the risk for dysfunctional worry. In this study, the Cronbach alpha coefficient was 0.907.

Self-efficacy expectations during nursing school regarding the ability to accomplish goals while in nursing school was measured using the General Perceived Self-Efficacy scale ${ }^{[49]}$. This scale was comprised of 10 items using a 4-point Likert scale with the ratings of: $1=$ not true at all, $2=$ hardly true, $3=$ moderately true, and $4=$ exactly true. The authors of this instrument note that the higher the score, the higher self-efficacy expectations held by the individual and report Cronbach's coefficient alphas ranging from 0.76 to 0.90 with most scores in the high $0.80 \mathrm{~s}^{[50]}$. In this study, the Cronbach alpha coefficient was 0.963 . Lastly, response of either pass or fail was used to obtain data about NCLEX result.

\subsection{Data collection and analysis}

Once Institutional Review Board approval was obtained, data collection procedures began. Deans, directors, or chairpersons of the nursing departments and the Office of Protection of Research Subjects of each selected institution were contacted via email to describe the purpose of the study and obtain permission to recruit senior nursing students as participants. A recruitment letter and flyer was also sent for distribution to the students via the institution's communication procedure.

The recruitment letter invited senior nursing students to participate in the study. The letter described the purpose of the study, confidentiality issues, the participant's role, compensation issues, and contact information for the investigators of the study. The recruitment flyer summarized the information from the letter and asked interested students to email his or her "after graduation" email address and date of graduation to the researcher at the provided email address.

Data collection was conducted after the student graduated by sending the electronic survey to the participant's "after graduation" email. At 3 weeks and 4 weeks following the graduation date, the researcher sent an email to the interested participant reminding him or her of the study. Six weeks after the graduation date the researcher sent an email providing the Survey Monkey link and directions for access and submission of the survey. A follow-up reminder email that contained the Survey Monkey link was sent 1 week later ( 7 weeks after graduation). Additionally, upon submission of the survey, the participant received a $\$ 5.00$ gift certificate from Amazon.com. All information gathered in this study was kept confidential, with no reference made in written or oral materials linking the participant to the study. In total, the survey link for accessing the electronic survey in Survey Monkey was sent to 214 individuals. Of the 214 individuals, 196 participated and returned the survey. However, 183 participants were included in the data analysis procedures because 13 participants did not answer the question about NCLEX outcome. 
The Statistical Package for the Social Sciences (SPSS $\left.{ }^{\circledR}\right)$ Graduate Pack 15.0 for Windows ${ }^{\circledR}$ was used to analyze the data. Descriptive statistics were conducted for the demographic information collected in this study. A block approach for logistic regression analysis was used and two models were tested. The first model answered Research Question 1 and investigated the academic or self-efficacy variables that influence NCLEX passage. The second model answered Research Question 2 and examined the nonacademic or self-efficacy variables that influence NCLEX passage. Additionally, the Chi-Square test for Independence was conducted to identify a relationship between primary language spoken and NCLEX outcome.

The assumptions considered with logistic regression included: (a) sample size, (b) multicollinearity, (c) independence of errors, and (d) outliers. Vittinghoff and McCulloch (2006) noted a minimum of 10 cases per predictor variable is adequate for logistic regression analysis ${ }^{[51]}$. The final sample totaled 183 . Also, 53.5\% $(\mathrm{n}=105)$ of the 196 participants did not record a verbal SAT score; thus, the verbal SAT score was excluded from the study. Therefore, the final total for predictors for inclusion in the logistic regression analysis was 13 . Hence, sample size for this study was adequate because it included 13 predictor variables, requiring a minimum sample size of 130 .

In addition, correlations were checked and all values were less than .7. A bivariate correlation of .7 or more may indicate multicollinearity ${ }^{[52]}$. Collinearity diagnostics were also done and tolerance values and variance inflation factor (VIF) values were acceptable. Also, a single case was represented in the data only once, therefore outcomes were statistically independent and final analysis demonstrated no outliers were present.

Correlation analysis using Pearson product-moment correlation coefficient was utilized to answer Research Question Number 3, identifying relationships that exist among self-efficacy, academic, and nonacademic variables of NCLEX passage. The assumptions considered with this data analysis technique included level of measurement, related pairs, independence of observations, and linearity ${ }^{[53]}$. None of the assumptions were violated.

Although not directly related to data collection, the researcher monitored email requests to prepare for a retake of the NCLEX with three students requesting assistance. For each of these students, an assessment plan was used to determine the student's needs and an individualized plan of study was recommended. All correspondence was done via email and at no time during this preparation period was identifying information requested. These three students followed up, reporting they passed the NCLEX on the retake.

\section{Results}

Recruitment information was sent to the deans, directors, or chairpersons of 79 universities for distribution to students. Of these 79 universities, 27 (34.1\%) were located in the South, 20 (25.3\%) in the West, 16 (20.2\%) in the Midwest, and 16 $(20.2 \%)$ in the North Atlantic.

\subsection{Participants}

There were 214 individuals interested in participating in the study. Data was collected for a period of 7 months and of these 214 individuals, 196 (91.5\%) participated and returned the electronic survey. For the question regarding NCLEX outcome, $183(93 \%)$ participants answered the question, whereas $13(6 \%)$ did not. Of the 183 who provided data for the dependent variable, $86.9 \%(n=159)$ recorded a pass and $13.1 \%(n=24)$ recorded a fail. The 13 participants who did not respond to the NCLEX outcome survey question were not included in the data analysis procedures, resulting in the final $\mathrm{n}=183$.

\subsection{Demographics}

A description of the sample and the NCLEX outcome is noted in Table 1. Although demographics were not studied as predictors of NCLEX outcome, demographic data was collected to provide additional information about the sample. Some 
findings include the following. The majority of the study sample $(89.1 \% ; n=163)$ reported their gender as female. The range of ages was 20 to 54 years with a mean age of 25.53 and standard deviation of 6.253 .

Table 1. Description of the Sample and NCLEX Outcome

\begin{tabular}{|c|c|c|c|c|}
\hline \multirow{2}{*}{ Demographic } & \multirow{2}{*}{$\begin{array}{l}\text { Finding } \\
\% \text { (number) }\end{array}$} & \multicolumn{3}{|c|}{ NCLEX Outcome } \\
\hline & & $\mathbf{N}$ & Pass & Fail \\
\hline \multirow{2}{*}{ Gender } & Female $=89.1(163)$ & 163 & 143 & 20 \\
\hline & Male $=10.9(20)$ & 20 & 16 & 4 \\
\hline \multirow{3}{*}{ Age } & Range $=20-54$ & & & \\
\hline & Mean $=25.53$ & & & \\
\hline & $\mathrm{SD}=6.253$ & & & \\
\hline \multirow{7}{*}{ Race/ethnicity } & Caucasian $=82.5(151)$ & 151 & 139 & 12 \\
\hline & Hispanic $=8.7(16)$ & 16 & 8 & 8 \\
\hline & Black $=4.4(8)$ & 8 & 7 & 1 \\
\hline & Filipino $=0.5(1)$ & 1 & 1 & 0 \\
\hline & Asian $=0.5(1)^{*}$ & 1 & 0 & 1 \\
\hline & American $/$ East Indian $=0.5(1)$ & 1 & 0 & 1 \\
\hline & Other $=2.7(5)^{* *}$ & 5 & 4 & 1 \\
\hline Grew up in U.S. & $94(172)$ & 172 & 150 & 22 \\
\hline Did not grow up in U.S. & $6(11)$ & 11 & 9 & 2 \\
\hline \multirow{3}{*}{ Years lived in U.S. } & Range $=3-30$ & & & \\
\hline & Mean 12.5 & & & \\
\hline & $\mathrm{SD}=7.512$ & & & \\
\hline \multirow{3}{*}{ Primary language } & English $=92.9(170)$ & 170 & 152 & 18 \\
\hline & Spanish $=3.8(7)$ & 7 & 1 & 6 \\
\hline & Other $=3.3(6)^{* * *}$ & 6 & 6 & 0 \\
\hline \multirow{4}{*}{ Location of school } & North Atlantic $=50(91)$ & 91 & 81 & 10 \\
\hline & South $=19.2(35)$ & 35 & 35 & 0 \\
\hline & West $=19.8(36)$ & 36 & 26 & 10 \\
\hline & Midwest = 11(20) & 20 & 16 & 4 \\
\hline \multirow{2}{*}{ School type } & Private $=49.2(90)$ & 90 & 81 & 9 \\
\hline & Public $=50.8(93$ & 93 & 78 & 15 \\
\hline
\end{tabular}

Note. *Asian includes Chinese, Japanese, Korean; **Other includes Eskimo, Inuit; ***Other includes Chinese, Japanese, Korean

$\mathrm{SD}=$ standard deviation

Most of the participants $(94 \% ; n=172)$ grew up in the U.S. and the primary language spoken by the study participants was English $(92.9 \% ; \mathrm{n}=170)$. In addition, most participants $(50 \% ; \mathrm{n}=91)$ indicated that the nursing program was located in the North Atlantic. Lastly, the findings regarding the type of baccalaureate nursing program (private or public) attended were essentially evenly distributed.

\subsection{Findings of the research questions}

Research Question 1. Of these 169 cases, 87\% $(n=147)$ reported a pass on the NCLEX and 13\% $(n=22)$ reported a fail. The model revealed statistical significance, $\chi^{2}(\mathrm{n}=169)=56.338, p=.000$. As shown in Table 2, the course grade that 
yielded a statistically significant contribution to the model was the medical-surgical grade showing an odds ratio (OR) of 1.176 and a $p=.021$. Additionally, self-efficacy expectations is statistically significant showing an OR of 1.258 and a $p=$ .011. This analysis indicates that the medical-surgical nursing grade and self-efficacy influence NCLEX passage.

Table 2. Significance, Odds Ratio, and CI for Academic and Self-Efficacy Variables

\begin{tabular}{lllll}
\hline \multirow{2}{*}{ Variable } & Sig. & \multirow{2}{*}{ Odds Ratio } & \multicolumn{3}{c}{ 95\% CI for Odds Ratio } \\
\cline { 3 - 5 } & & & Lower & Upper \\
\hline College chemistry & .957 & 1.003 & .899 & 1.120 \\
Fundamentals & .082 & 1.125 & .985 & 1.286 \\
Medical-surgical & .021 & 1.176 & 1.025 & 1.350 \\
Pharmacology & .072 & 1.127 & .989 & 1.283 \\
Leadership/Management & .226 & .944 & .859 & 1.036 \\
Self-efficacy expectations & .011 & 1.258 & 1.054 & 1.502 \\
\hline
\end{tabular}

Note. Sig. $=$ significance $\mathrm{CI}=$ confidence interval

Research Question 2. Of the 179 cases, 87\% $(n=156)$ reported a pass on the NCLEX and $13 \%(n=23)$ reported a fail. The model revealed statistical significance, $\chi^{2}(n=179)=39.367, p=.000$, indicating that the model was able to distinguish between respondents who reported a pass on the NCLEX and those who did not. As shown in Table 3, one of the independent variables made a statistically significant contribution to the model (home and family) showing a $p=.039$. In this subscale (home and family), the event that demonstrated the strongest influence was a major change in health or behavior of a family member $(n=64,35 \%)$. Following this event, a major change in living conditions $(n=49,26.8 \%)$ and a change in family get-togethers $(n=46,25.1 \%)$ were events that had some influence on home and family events and responsibilities. Three of the study variables were marginal but not significant; these were: (a) financial, $p=.055$, (b) personal and social, $p=.061$, and (c) work, $p=.066$. Additionally, self-efficacy expectations were statistically significant showing an OR of 1.231 and a $p=.006$. The Chi-square test for independence indicated a significant relationship between primary language spoken and NCLEX result, $\chi^{2}(\mathrm{n}=183)=34.237, p=.000$. Of importance to note is that of the 7 participants who selected Spanish as the primary language spoken, $85.7 \%(\mathrm{n}=6)$ failed the NCLEX and $14.3 \%(\mathrm{n}=1)$ passed. This analysis indicates that the nonacademic variables influencing NCLEX passage is primary language spoken, home and family events and responsibilities, and self-efficacy expectations.

Table 3. Significance, Odds Ratio, and CI for Nonacademic and Self-Efficacy Variables

\begin{tabular}{lllll}
\hline \multirow{2}{*}{ Variable } & Sig. & \multirow{2}{*}{ Odds Ratio } & \multicolumn{2}{c}{ 95\% CI for Odds Ratio } \\
\cline { 4 - 5 } & & & Lower & Upper \\
\hline Primary language spoken & .842 & .889 & .279 & 2.831 \\
Worry & .133 & .923 & .831 & .025 \\
Health & .385 & .995 & .984 & 1.006 \\
Work & .066 & 1.011 & .999 & 1.023 \\
Home and family & .039 & .994 & .989 & 1.000 \\
Personal and social & .061 & 1.007 & .000 & 1.013 \\
Financial & .055 & .985 & 1.063 & 1.000 \\
Self-efficacy expectations & .006 & 1.231 & 1.425 \\
\hline
\end{tabular}

Note. Sig. = Significance; $\mathrm{CI}=$ Confidence Intervals

Research Question 3. Correlation analysis using Pearson product-moment correlation coefficient revealed that all academic variables showed a positive correlation with self-efficacy, indicating that as the course grade improved, self-efficacy increased. For the nonacademic variables, negative correlations were noted between the variable and 
self-efficacy indicating an inverse effect between the variable and self-efficacy. Table 4 displays a correlation matrix of these findings.

Table 4. Correlation Matrix: Pearson Correlations of Variables and Self-Efficacy

\begin{tabular}{|c|c|c|c|c|c|c|c|c|c|c|c|c|}
\hline & Chem & Fund & MS & Phar & LM & Worry & $\mathbf{H}$ & $\mathbf{W}$ & HF & PS & $\mathbf{F}$ & SEE \\
\hline Chem & 1.00 & & & & & & & & & & & \\
\hline Fund & .439 & 1.00 & & & & & & & & & & \\
\hline MS & .476 & .585 & 1.00 & & & & & & & & & \\
\hline Phar & .582 & .501 & .563 & 1.00 & & & & & & & & \\
\hline LM & .553 & .618 & .582 & .524 & 1.00 & & & & & & & \\
\hline Wor & -.188 & -.056 & -.161 & -.161 & -.141 & 1.00 & & & & & & \\
\hline $\mathrm{H}$ & -.015 & .044 & -.031 & -.083 & -.001 & .323 & 1.00 & & & & & \\
\hline W & .003 & .047 & .005 & -.074 & .040 & .303 & .381 & 1.00 & & & & \\
\hline $\mathrm{HF}$ & -.071 & .000 & -.145 & -.159 & -.106 & .324 & .268 & .343 & 1.00 & & & \\
\hline PS & .027 & .104 & .018 & -.047 & .017 & .221 & .504 & .248 & .252 & 1.00 & & \\
\hline $\mathrm{F}$ & -.115 & -.039 & -.069 & -.128 & -.077 & .216 & .236 & .276 & .415 & .260 & 1.00 & \\
\hline SEE & .311 & .297 & .225 & .258 & .326 & -.312 & -.078 & -.058 & -.195 & -.005 & -.134 & 1.00 \\
\hline
\end{tabular}

Chem = Chemistry; Fund = Fundamentals; MS = medical-surgical; Phar = Pharmacology; LM = leadership/management; Wor = worry; $\mathrm{H}=$ health; $\mathrm{W}=$ work; HF = home and family; PS

$=$ personal and social; $\mathrm{F}=$ financial; $\mathrm{SEE}=$ self-efficacy expectations

\subsection{Self-efficacy and final adjusted model}

Lastly, two additional logistic regression models were tested. First, self-efficacy was tested alone and the model revealed statistical significance, $\chi^{2}(\mathrm{n}=179)=21.071$, with an OR of $1.312, p=.000$ indicating that self-efficacy influenced NCLEX passage. Second, a final adjusted model was tested that included the medical-surgical grade, home and family events and responsibilities, and self-efficacy. The model revealed statistical significance, $\chi^{2}(\mathrm{n}=178)=51.720, p=.000$ and significant findings were noted for the medical-surgical grade and self-efficacy expectations. However, home and family events and responsibilities approached significance at $p=.07$.

\section{Discussion and conclusions}

Knowledge of the predictors for success on the NCLEX® will provide nurse educators with the essential knowledge needed to design strategies and tailor interventions to enhance student performance. However, most studies that investigated these predictors have focused on evaluating academic predictors. The purpose of this study was to identify the effect of not only selected academic predictors, but also nonacademic and self-efficacy variables on NCLEX outcomes. This information will provide additional knowledge to nursing science about predictors of NCLEX success.

\section{Limitations}

Though the results of this study are promising, three limitations must be considered when evaluating the findings. Because over one-half of the participants $(53.5 \%, \mathrm{n}=105)$ did not record a verbal SAT score, this variable was excluded from the statistical analysis. Exclusion was necessary because the loss of $53.5 \%$ of the sample compromised the analysis for logistic regression analysis.

Another limitation of this study related to the recruitment process. Before participants were allowed to be recruited from the universities selected for this study, the Institutional Review Board (IRB) of 18 universities required a formal review 
process. Pursuing participation for 8 of the universities requiring formal IRB approval was not compatible with the timing of this study; thus students from these universities did not get the opportunity to participate.

In addition, the recruitment process was affected by recruiting participants the month before graduation. The researcher did not consider that at this time senior students would be preparing for several events related to the program completion process, a major priority for many students. Introducing the research study early in the final semester of the nursing program may have resulted in greater participation.

Lastly, the researcher of this study had to rely on others to introduce the study to potential participants and distribute recruitment materials. Although directions were provided for the distribution of recruitment materials, it was difficult to know exactly if the same procedures were followed throughout. Although follow-up was conducted with the participating universities, the researcher could not ensure that materials reached the potential participants. Enrolling students to participate in the study would have been more effective if student and researcher had face-to-face contact. However, because universities that participated were located throughout the nation this enrollment method was not feasible.

\subsection{Academic variables}

This study found that the medical-surgical grade has a relationship with NCLEX passage. These findings are congruent with what other studies found and substantiate the importance of acquisition of nursing knowledge ${ }^{[2,5,6,14,18-20]}$. For nursing education, these findings imply that medical-surgical nursing courses need to be a priority in curriculum planning, and the integration of medical-surgical nursing in all other courses should be considered. Furthermore, because medicalsurgical nursing concepts are tested on NCLEX, medical-surgical nursing courses need to be one cornerstone of the curriculum so that students are successful with NCLEX. Likewise, to continue to support the new development of curriculum, faculty need to consider conducting studies in their program on how to structure nursing courses to ensure NCLEX success. This could be fruitful in terms of providing the nursing program with specific information about how to improve their curriculum.

\subsection{Nonacademic variables}

A few researchers have been interested in nonacademic predictors, such as test anxiety, self-esteem, and personal and environmental issues. Arathuzik and Aber (1998) noted significant correlations between success and lack of family demands or responsibilities, lack of emotional stress, and sense of competency ${ }^{[23]}$. Additionally, these researchers indicated that students who did not speak English as the primary language at home did not do well on NCLEX ${ }^{[23]}$.

Poorman and Martin (1991) found that variables other than academic ones were the best predictors of actual NCLEX scores and these nonacademic variables included self-predicted NCLEX scores and self-perceived grades ${ }^{[24]}$. Other studies showed that test anxiety and stress have been linked to performance on exams ${ }^{[25,26]}$ and Campbell and Dickson's (1996) results demonstrated that test anxiety and self-concept/esteem showed some correlation with NCLEX success ${ }^{[7]}$.

This study demonstrated that self-efficacy expectations while in school had a strong effect on NCLEX success. Additionally, the correlation analysis revealed that all academic variables showed a positive correlation with self-efficacy, indicating that as the course grade improved, self-efficacy increased. For the nonacademic variables, negative correlations were noted between worry and personal events and responsibilities. As worry and personal responsibilities increased while in school, self- efficacy decreased. Therefore, findings indicate that the more confident a student is the better he or she will perform. This result points to the critical need for nurse educators to look at ways to support or increase a student's self-confidence.

This study also demonstrated that home and family events and responsibilities influence NCLEX success. This information may assist nurse educators to consider informing students about the need for them to seek out assistance from faculty if home and family events present obstacles to learning, so that faculty are able to direct them to university 
resources and support systems. Finally, this study noted that the primary language spoken affected NCLEX outcome and that non-English speaking individuals are at greater risk for failure than English speaking students. Therefore, nurse educators should also institute assessment strategies early in the nursing program so that high-risk students are identified and integrated into appropriate support services.

\section{Summary}

Nurse educators struggle with the problem of how to adequately prepare both a competent professional nurse and a successful NCLEX candidate. Despite educational preparation, there are times when students with high academic grades fail and those with low grades pass NCLEX. These outcomes alert the educator that there are other important variables affecting the outcome of NCLEX passage. The findings from this study demonstrate that self-efficacy, the medicalsurgical grade, home and family events and responsibilities, and primary language spoken have an important and significant effect on passing NCLEX. Thus, factors other than the academic ones may affect NCLEX success. It is important that faculty look at these new nonacademic variables along with self-efficacy so as to integrate resources and programs to support student NCLEX success.

\section{Competing interests}

The authors declare that they have no competing interests or conflicts of interest.

\section{Authors' contributions}

All authors of this article have made significant contributions to this manuscript with regard to its design, acquisition of data, analyzing and interpreting data, and drafting and revising the manuscript for its final version.

\section{Acknowledgments}

The authors would like to acknowledge Dr. Tish Smyer, Dr. Mary Bondmass, and Dr. Sajjad Ahmad for their support of this research study.

\section{References}

[1] McGahee T, Gramling L, Reid T. NCLEX-RN® Success: Are there predictors? South Online. J Nurs Res 2010 ; 10.

[2] Alexander JE. A five-year study of graduates' performance on NCLEX-RN. J Nurs Educ 1997; 36:443-445. PMid:9362029

[3] Briscoe V, Anema M. The relationship of academic variables as predictors of success on the National Council Licensure Examination for Registered Nurses (NCLEX-RN) in a selected associate degree program. ABNF J 1999; 10: 80-83. PMid:10745713

[4] Daley LK, Kirkpatrick BL, Frazier SK, Chung ML, Moser DK. Predictors of NCLEX-RN success in a baccalaureate nursing program as a foundation for remediation. J Nurs Educ 2003; 42: 390-398. PMid:13677554

[5] Roncoli M, Lisanti P, Falconi A. Characteristics of baccalaureate graduates and NCLEX-RN performance. J N Y State Nurses Assoc 2000;31:17-19.

[6] Beeson A, Kissling G. Predicting success for baccalaureate graduates on the NCLEX-RN. J Prof Nurs 2001;17:121-127. PMid:11391557 http://dx.doi.org/10.1053/jpnu.2001.23382

[7] Campbell AR, Dickson CJ. Predicting student success: A 10-year review using integrative review and meta-analysis. J Prof Nurs 1996; 12: 47-59. http://dx.doi.org/10.1016/S8755-7223(96)80074-3

[8] Crow C, Handley M, Morrison, R, Shelton M. Requirements and interventions to promote and predict NCLEX-RN success: A national study. J Prof Nurs 2004; 20: 174-186. PMid:15211427 http://dx.doi.org/10.1016/j.profnurs.2004.04.004

[9] Foti I, De Young S. Predicting success on the National Council Licensure Examination-Registered Nurse: Another piece of the puzzle. J Prof Nurs 1991; 7: 99-104. http://dx.doi.org/10.1016/8755-7223(91)90093-Z

[10] Krupa K, Quick MM, Whitney T. The effectiveness of nursing grades in predicting performance on the NCLEX-RN. J Prof Nurs 1988; 4: 294-298. http://dx.doi.org/10.1016/S8755-7223(88)80017-6 
[11] McKinney J, Small S, O'Dell N, Coonrod, BA. Identification as predictors of success for the NCLEX and students at risk for NCLEX failure in a baccalaureate nursing program. J Prof Nurs 1988; 4: 55-59. http://dx.doi.org/10.1016/S8755-7223(88)80074-7

[12] Quick MM, Krupa K, Whitney T. Using admission data to predict success in the NCLEX-RN in a baccalaureate program. J Prof Nurs 1985;1:364-368. http://dx.doi.org/10.1016/S8755-7223(85)80060-0

[13] Seldomridge L, DiBartolo M. Can success and failure be predicted for baccalaureate graduates in the computerized NCLEX-RN? J Prof Nurs 2004;20:361-368. PMid:15599869 http://dx.doi.org/10.1016/j.profnurs.2004.08.005

[14] Stuenkel D. At-risk Students: Do theory grades + standardized examinations = success? Nurse Educ 2006; $31: 207-212$. PMid:16980824 http://dx.doi.org/10.1097/00006223-200609000-00007

[15] Waterhouse JK, Beeman PB. Predicting NCLEX-RN success: Can it be simplified? Nurs Educ Perspect 2003; 24 : 35-39. PMid:12674919

[16] Mills A, Becker A, Sampel M., Pohlman V. Success-failure on the National Council Licensure Examination for Registered Nurses by nurse candidates from an accelerated baccalaureate nursing program. J Prof Nurs 1992; 8: 351-357. http://dx.doi.org/10.1016/8755-7223(92)90098-J

[17] Waterhouse JK, Carroll MC, Beeman PB. National Council Licensure Examination success: Accurate prediction of student performance on the post-1988 examination. Journal of Professional Nursing, 1993; 9: 278-283. http://dx.doi.org/10.1016/8755-7223(93)90053-F

[18] Beeman P, Waterhouse J. NCLEX-RN performance: Predicting success on the computerized examination. J Prof Nurs 2001; 17: 158-165. PMid:11464336 http://dx.doi.org/10.1053/jpnu.2001.24860

[19] Barkley T, Rhodes R, Dufour C. Predictors of success on the NCLEX-RN among baccalaureate nursing students. Nurs Health Care Perspect 1998; 14: 133-137.

[20] Endres D. A comparison of predictors of success on NCLEX-RN for African American, foreign-born, and white baccalaureate graduates. J Nurs Educ 1997; 36: 365-371. PMid:9348478

[21] Young, A, Willson, P. Predicting NCLEX-Success: The Seventh Validity Study HESI Exit Exam. CIN: Comp, Infor, Nurs 2012; 30:55-60.

[22] Nibert, A, Young, A, Adamson, C. Predicting NCLEX Success with the HESI Exam: Fourth annual validity study CIN: Comp, Infor, Nurs 2008S; 26: 28S-34S. PMid:18791387

[23] Arathuzik D, Aber C. Factors associated with National Council Licensure Examination-Registered Nurse Success. J Prof Nurs 1998; 14: 119-126. http://dx.doi.org/10.1016/S8755-7223(98)80040-9

[24] Poorman S, Martin J. The role of nonacademic variables in passing the National Council Licensure Examination. J Prof Nurs 1991; 7: 25-32. http://dx.doi.org/10.1016/8755-7223(91)90071-R

[25] Hight L. A comparative study of anxiety levels in traditional and nontraditional undergraduate nursing students in Tennessee. Unpublished Ed. D. Memphis: The University of Memphis, 1996.

[26] Mills L, Wilson C, Bar B. A holistic approach to promoting success on NCLEX-RN. J Holist Nurs 2001; 19: 360-374. PMid:11847843 http://dx.doi.org/10.1177/089801010101900405

[27] Bandura A. Social learning theory. Upper Saddle River, NJ: Pearson Prentice Hall, 1977.

[28] Gore, P. Academic self-efficacy as a predictor of college outcomes: Two incremental validity studies. J of Career Assessment 2006; 14: 92-115. http://dx.doi.org/10.1177/1069072705281367

[29] Pajares, F. Self-efficacy beliefs in academic settings. Review of Ed Research 1996; 66: 543-578.

[30] Bong, M. Academic motivation in self-efficacy, task value, achievement goal orientations, and attributional beliefs. The J of Ed Research 2004; 97: 287-297. http://dx.doi.org/10.3200/JOER.97.6.287-298

[31] Bong, M, Skaalvik, E. Academic self-concept and self-efficacy: How different are they really? Ed Psych Rev 2003 ; 15 : 1-40. http://dx.doi.org/10.1023/A:1021302408382

[32] Linnenbrink, E. Pintrich, P. The role of self-efficacy beliefs in student engagement and learning in the classroom. Reading and Writing Quarterly 2003; 19: 119-137. http://dx.doi.org/10.1080/10573560308223

[33] Pajares, F. Self-efficacy beliefs, motivation and achievement in writing: A review of the literature. Reading and Writing Quarterly 2003; 19: 139-158. http://dx.doi.org/10.1080/10573560308222

[34] Pajares, F. Schunk, D. Self-beliefs and school success: Self-efficacy, self concept, and school achievement. 2001. In: Perception. Riding, R. \& Rayner, S. (Eds.).London: Ablex Publishing.

[35] Schunk, D.H. Self-efficacy and academic motivation. Ed Psychologist 1991; 26;207-231.

[36] Schunk D.H.Self-efficacy, motivation, and performance. J App Sport Psych 1995; 7: 112-137. http://dx.doi.org/10.1080/10413209508406961

[37] Schunk, D.H. Self-efficacy for reading and writing: Influence of modeling, goal setting and self-evaluation. Reading and Writing Quarterly 2003; 19: 159-172. http://dx.doi.org/10.1080/10573560308219 
[38] Pajares, F. Current directions in self-efficacy research. 1991. In Maehr, M. \& Pintrich,P. R. Advances in Motivation and Achievement. (pp. 1-49). Greenwich, CT: JAI Press.

[39] Zimmerman, B. J. Bandura, A. Martinez-Pons, M. Self-motivation for academic attainment: The role of self-efficacy beliefs and personal goal setting. Amer Ed Psych 1992; 82: 51-59. http://dx.doi.org/10.1037/0022-0663.82.1.51

[40] Goldenberg, D. Iwasiw, C. MacMaster, E. Self-efficacy of senior baccalaureate nursing students and preceptors. Nurs Education Today, 1997; 17: 303-310. http://dx.doi.org/10.1016/S0260-6917(97)80061-5

[41] Madorin, S. Iwasiw, C. The effects of computer-assisted instruction on the self-efficacy of baccalaureate nursing students. J Nurs Educators 1999;38:282-285.

[42] Andrew, S. Self-efficacy as a predictor of academic performance in science. J Adv Nurs1998;27: 596-603. PMid:9543047 http://dx.doi.org/10.1046/j.1365-2648.1998.00550.x

[43] Hodge, M. Do anxiety, math self-efficacy and gender affect nursing students' drug dosage calculations? Nurs Educator 1999; 24: 36-41. PMid:10647389 http://dx.doi.org/10.1097/00006223-199907000-00010

[44] Harvey,V. McMurray, N. Self-efficacy: A means of identifying problems in nursing education and career progress. Inter J of Nurs Studies 1994; 31: 471-485. http://dx.doi.org/10.1016/0020-7489(94)90017-5

[45] Bandura, A. On the functional properties of perceived self-efficacy revisited. J of Management. 2012; 38: 9-44. http://dx.doi.org/10.1177/0149206311410606

[46] Femea P, Gaines C, Braithwaite D, Abdur-Rahman V. Sociodemographic and academic characteristics of linguistically diverse nursing students in a baccalaureate degree nursing program. J Multicult Nurs Health 1995;1:24-29.

[47] Miller M, Rahe R. Life changes scaling for the 1990s. J Psychosom Res 1997; 43: 279-292. http://dx.doi.org/10.1016/S0022-3999(97)00118-9

[48] Gladstone G, Parker G, Mitchell P, Malhi G, Wilhelm K, Austin MP. A brief measure of worry severity (BMWS): Personality and clinical correlates of severe worriers. J Anx Disord 2005; 19: 877-892. PMid:16243636 http://dx.doi.org/10.1016/j.janxdis.2004.11.003

[49] Scholz U, Gutierrez Dona B, Sud S, Schwarzer R. Is general self-efficacy a universal construct? Eur J Psychol Assess 2002; 18: 242-251. http://dx.doi.org/10.1027//1015-5759.18.3.242

[50] Schwarzer R, Jerusalem M. Generalized self-efficacy scale. In Measures in health psychology: A user's portfolio. Causal and control beliefs. J. Weinman, S. Wright, M. Johnson. Windsor, UK: NFER-NELSON, 1995, 35-37.

[51] Vittinghoff E, McCulloch C. Relaxing the rule of ten events per variable in logistic and cox regression. Am J Epidemiol 2006. PMid:17182981

[52] Tabachnick B, Fidell L. Using multivariate statistics (5th ed.). New York: Pearson Education, 2007.

[53] McLaughlin F, Marascuilo L. Advanced nursing and health care research: Quantification approaches. Philadelphia: Saunders, 1990. 